\title{
Recombinant tissue plasminogen activator following paediatric cataract surgery
}

\author{
J S Mehta, G G W Adams
}

\begin{abstract}
Background-The use of recombinant tissue plasminogen activator (r-TPA) has been advocated in the treatment of postsurgical fibrinous membrane formation following cataract surgery in adults. Its use in paediatric cases is not well documented. Method-A retrospective review of paediatric cataract extractions performed at Moorfields Eye Hospital between 1 January 1997 and 4 April 1999 was carried out. Results-Cataract extractions were performed in 37 patients, 22 in males 15 in females. Four $(9.2 \%)$ underwent intracameral injection of $25 \mu \mathrm{g}$ r-TPA. They were all females of Afro-Caribbean origin. The time to injection varied from 4-14 days, mean 7.2 days. Complete resolution of the fibrinous membrane was seen in all cases. There were no complications by the 3 month follow up.

Conclusion-r-TPA may be used safely and effectively at a dose of $25 \mu \mathrm{g}$ for the treatment of severe fibrinous membranes following paediatric cataract extraction. It aided the visual recovery of the children and also allowed a reduced regimen of topical steroid therapy to be used postoperatively.
\end{abstract}

(Br F Ophthalmol 2000;84:983-986)

Fibrous effusion into the anterior chamber is a rare complication of uneventful cataract surgery. However, if it occurs visual recovery is delayed and intensive topical or systemic anti-inflammatory treatment is required. Intracameral injection of recombinant tissue plasminogen activator ( $r$-TPA) has been advocated for treatment of postsurgical fibrinous membrane formation in adults ${ }^{1}$ following cataract surgery. Its use in paediatric cataract surgery has only recently been observed. ${ }^{2}$

Materials and methods

We performed a retrospective review of paediatric patients ( 1 month to 8 years old) who underwent cataract surgery at Moorfields Eye Hospital from January 1997 to April 1999. We then analysed the number of eyes that received r-TPA intracamerally secondary to severe fibrinous pupillary membrane formation following surgery. Information on complications, outcome, and success of treatment was compared.

The same surgeon (GGWA) performed all the surgical procedures for patients who received additional $r$-TPA. General anaesthesia was used in all cases. A limbal incision was made and the anterior chamber entered using a blade. The aqueous humour was exchanged with Healon. An initial opening was made in the anterior capsule using a cystotome, and nuclear aspiration was performed using a Simcoe. Anterior capsulorhexis was completed. The anterior chamber was reinflated with Healon, the incision enlarged, and a one piece poly(methyl methacrylate) (PMMA) intraocular lens implanted into the capsular bag (Table 1). No primary posterior capsulorhexis was performed. Residual viscoelastic was removed using the Simcoe, $0.01 \%$ Miochol inserted, and the wound closed with interrupted 10-0 nylon. At the end of the procedure subconjunctival Zinacef and Betnesol was injected and the eye covered with a shield. For the first week after cataract surgery all patients received dexamethasone eye drops 2 hourly, chloramphenicol eye drops 2 hourly, and cyclopentolate eye drops $1 \%$ twice daily to reduce the postoperative inflammatory response. No patients received oral steroids.

The r-TPA was prepared in the Moorfields Eye Hospital pharmacy by reconstitution of 20 $\mathrm{mg}$ of lyophilised tissue plasminogen activator in $20 \mathrm{ml}$ of sterile water according to the manufacturer's recommendations. All preparation was under a sterile hood. The reconstituted r-TPA was diluted 1:4 in sterile balanced salt solution which was then divided into multiple aliquots of $1 \mathrm{ml}(250 \mu \mathrm{g})$ of r-TPA. The syringes were then stored at $-70^{\circ} \mathrm{C}$ in an ultralow freezer and before use the syringes were thawed to room temperature.

Table 1 Details of patients

\begin{tabular}{|c|c|c|c|c|c|c|c|c|}
\hline \multirow[b]{3}{*}{ Patient } & \multirow[b]{3}{*}{ Age } & \multirow[b]{3}{*}{ Sex } & \multirow[b]{3}{*}{ IOL inserted } & \multirow[b]{3}{*}{ Days to injection } & \multirow[b]{3}{*}{ Complications } & \multicolumn{3}{|l|}{ Visual acuity } \\
\hline & & & & & & \multirow[b]{2}{*}{ Preinjection } & \multicolumn{2}{|c|}{ Postinjection } \\
\hline & & & & & & & $1 / 52$ & $3 / 12$ \\
\hline 1 & 7 years & $\mathrm{F}$ & Chiron Vision-IO LAB & 7 days, dose $25 \mu \mathrm{g}$ & Mild residual fibrin & $6 / 60$ & $6 / 12$ & $6 / 6$ \\
\hline 2 & 4 years & $\mathrm{F}$ & $\begin{array}{l}\text { Pharmacia-Heparin } \\
\text { coated }\end{array}$ & 4 days, dose $10 \mu \mathrm{g}$ & Nil & $3 / 60$ & $6 / 18$ & $6 / 18$ \\
\hline 3 & 5 years & $\mathrm{F}$ & Chiron Vision IO LAB & 14 days, dose $25 \mu \mathrm{g}$ & $\begin{array}{l}\text { Residual posterior } \\
\text { synechiae }\end{array}$ & $2 / 60$ & $6 / 12$ & $6 / 9$ \\
\hline 4 & 6 years & $\mathrm{F}$ & Chiron Vision IO LAB & 4 days, dose $25 \mu \mathrm{g}$ & $\begin{array}{l}\text { Residual posterior } \\
\text { synechiae }\end{array}$ & $6 / 60$ & $6 / 24$ & $6 / 18$ \\
\hline
\end{tabular}




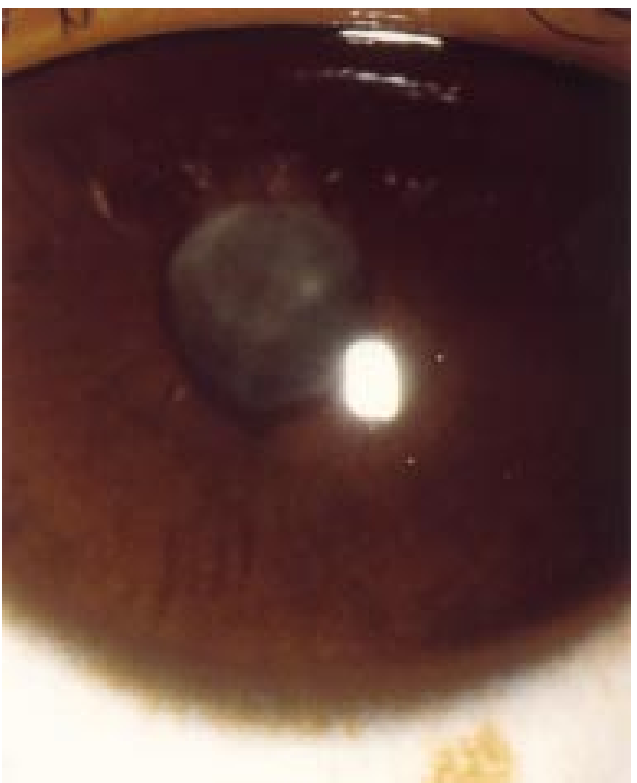

Figure 1 Pupillary membrane formation following cataract extraction.

The patients were all treated under a general anaesthetic because of their age and inability to cope with injection under local anaesthesia. The injections were performed with the patient in the supine position with a lid speculum inserted to separate the lids. A sterile 30 gauge cannula was placed on the syringe and $0.1 \mathrm{ml}$ $(25 \mu \mathrm{g}) \mathrm{r}$-TPA was injected into the anterior chamber through the original surgical incision.

Slit lamp examination was performed postoperatively after 2 hours, 1 day, 2 days, 3 days, and then weekly to assess complications and dissolution of the fibrin. Visual acuity was measured by Snellen or Sheridan-Gardiner acuity tests depending on the age of the patient.

\section{Results}

There were 37 patients who had undergone cataract extraction in the specified time period. There were 22 males and 15 females with an age range of 4 months to 7 years, mean age 4 years 6 months. There were 10 children of Afro-Caribbean origin; 32 children had congenital cataracts, and 30 had posterior chamber intraocular lens implants.

There were four patients who underwent additional treatment with intracameral r-TPA because of the presence of a severe fibrinous pupillary membrane (Fig 1). They were all females, of Afro-Caribbean origin, with congenital cataracts. Patient 4 underwent concomitant surgical peripheral iridectomy. One patient had a heparin coated IOL (patient 2), while the other patients had infusion lines constituted with heparin during their surgery.

The time to injection varied from 4 days to 14 days, mean 7.2 days. Following treatment with r-TPA there was residual posterior synechiae found in two cases (Fig 2) and mild residual fibrin in one case. There were no other complications noted after the injection up to a 3 month follow up period. Intraocular pressure remained within normal limits in all cases.

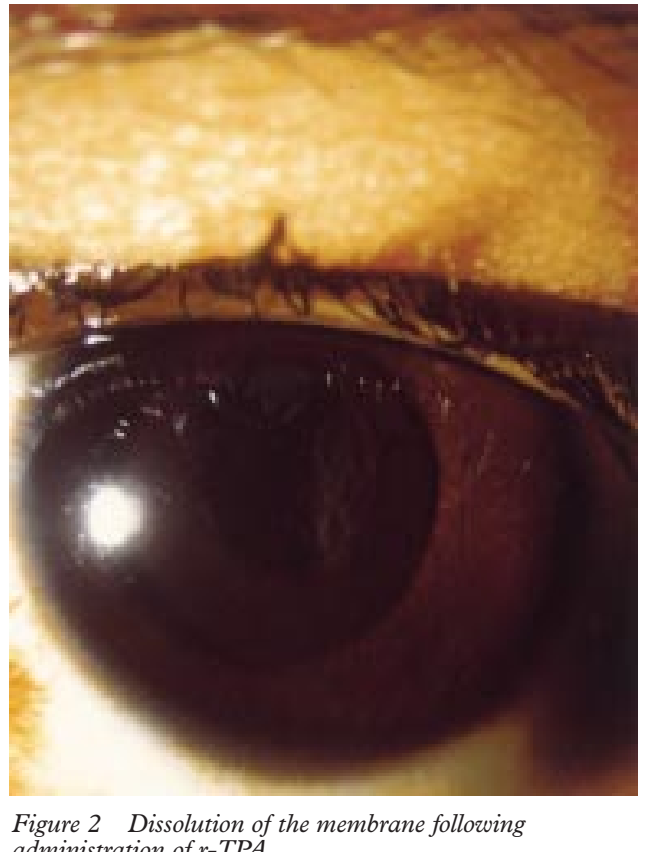
administration of $r-T P A$.

The time for complete dissolution of fibrin varied between the patients with only one patient showing complete dissolution by 1 hour. The other three patients had complete dissolution by the following day. All patients received Pred Forte 1 hourly, chloramphenicol eye drops two hourly, cyclopentolate eye drops $1 \%$ twice daily postinjection for at least a week until reviewed in clinic where the intensive steroid regimen was reduced with cessation of the other drops. Visual acuity improved by a minimum of three lines in the immediate postinjection period in all cases. Two patients, nos 2 and 4, underwent occlusion therapy postoperatively (Table 1).

\section{Discussion}

The pathogenesis of the postoperative fibrin response is unclear but it involves the breakdown of the blood-ocular barrier by inflammation and dysfunction of the coagulation and fibrinolytic pathways. ${ }^{3}$ Fibrin formation appears particularly in the pupillary area, where immune complex formation occurs. ${ }^{4}$ Risk factors for postoperative fibrin exudation in adults include diabetes, vitrectomy and silicone oil, glaucoma, uveitis, iris surgery, and pseudoexfoliation. ${ }^{5}$ Fibrinous membrane formation after cataract may cause many complications, including displacement of the intraocular lens, pupil block glaucoma, decreased visual acuity, photophobia, compromise in the structural and functional integrity of the cornea, trabecular meshwork, lens, uveal tissue, and side effects due to long term use of mydriatrics and steroids. ${ }^{6}$

In children implantation of a posterior chamber intraocular lens is a risk factor for an augmented postoperative intraocular inflammatory response. ${ }^{78}$ Particularly following paediatric cataract extraction, fibrinous membrane formation may cause a reduction in visual acuity, and hinder the potential for improvement in visual development during this sensitive 
period, hence the need for early intervention. ${ }^{2}$ Mild fibrinous membranes may be treated successfully with topical corticosteroids, nonsteroidal anti-inflammatory agents, and cycloplegics. However, for moderate to severe fibrinous membranes conventional treatment may need to be extended for several weeks and still may be unsuccessful. The duration of treatment may be associated with many complications and also it may be difficult to administer such intensive regimens to young children.

TPA (tissue plasminogen activator) is secreted by the vascular endothelial cells as well as the corneal epithelium/endothelium and trabecular meshwork. ${ }^{9}$ A significant decrease of TPA activity is found in the first days following cataract surgery and intraocular lens implantation. ${ }^{10}$ Fluctuations in the TPA concentration in the aqueous humour following cataract surgery associated with additional risk factors that enhance the breakdown of the blood-aqueous barrier may increase the risk of severe fibrinous membrane formation. ${ }^{5}$

Recombinant tissue plasminogen activator is a fibrinolytic serine protease that is genetically cloned and obtained by expression of recombinant DNA. ${ }^{11}$ Its fibrinolytic activity is based on the conversion of plasminogen into plasmin, which promotes fibrin degradation. r-TPA requires fibrin binding which enhances its affinity for plasminogen so that plasminogen activation is confined to the surface fibrin clot; hence, it is clot specific and is not associated with systemic fibrinolysis unlike streptokinase or urokinase. The plasma half life of intravenous r-TPA is approximately 7 minutes ${ }^{12}$ and with the low concentrations used for intraocular fibrinolysis the risk of systemic plasminogen activation is low. ${ }^{13}$ Streptokinase and urokinase have been previously used intraocularly but they were associated with large inflammatory responses and corneal toxicity. ${ }^{12}$

r-TPA has not been found to be damaging to the human corneal endothelium ${ }^{12}{ }^{14}$ or rabbit $^{15}$ anterior segment with no changes in corneal endothelium cell size or morphology even with doses as high as $200 \mu$ g. $^{6}$ Retinal toxicity increases with intravitreal doses between 50 $100 \mu \mathrm{g}$ in animal models. ${ }^{15}$

r-TPA has been used in cases of fibrinous effusion in adults after vitrectomy, ${ }^{16}$ penetrating keratoplasty, ${ }^{12}$ glaucoma surgery, ${ }^{17}$ traumatic hyphaema, ${ }^{18}$ and in patients undergoing surgical removal of choroidal neovascular membranes with age related macular degeneration. ${ }^{19}$ Following adult cataract surgery complete fibrinolysis has been achieved in $95 \%$ of cases receiving $25 \mu \mathrm{g}$ of r-TPA for moderate to severe fibrinous membrane formation. ${ }^{5}$ The mean time for effect was 3.3 hours. ${ }^{5}$ Moon et al reported complete fibrinolysis of moderate to severe fibrinous membranes after cataract surgery in $90 \%$ of 52 eyes also using $25 \mu \mathrm{g}$ of r-TPA but the maximum effect was observed 1 hour after injection. ${ }^{6}$ However, in a larger study $10 \mu \mathrm{g}$ r-TPA successfully accelerated fibrinolysis in $93 \%$ of adults by 2 weeks following cataract surgery. ${ }^{7}$ In the only other reported paediatric study Klais et al used
$10 \mu \mathrm{g}$ r-TPA and achieved complete dissolution in $90 \%$ of cases within 3 days. In our cases the time for complete fibrinolysis was longer than the adult series but similar to the series of Klais et al. We also found the use of the r-TPA allowed a shorter intensive course of topical steroids to be administered postoperatively.

The main complications of r-TPA use in adults postcataract surgery are anterior chamber haemorrhage, increase in IOP, and persistent posterior synechiae. ${ }^{1}$ The risk of haemorrhage may be reduced significantly if the r-TPA is not given before the third day ${ }^{5}$ after the cataract surgery and some have advised waiting 1 week. ${ }^{1}$ All our patients received r-TPA after a minimum time of 4 days and no haemorrhage was observed. However, haemorrhage is more likely to occur in patients with pre-existing rubeosis. ${ }^{20} \mathrm{~A}$ temporary increase in IOP up to $30 \mathrm{~mm} \mathrm{Hg}$ is noted in some studies after r-TPA injection but the pressure returned to normal in all the cases by $3-4$ days $^{1}$ without antiglaucoma treatment. The pressure increase may be due to transient blockage of the trabecular meshwork after fibrinolysis of thick membranes. ${ }^{5}$

Acute band keratopathy has been described in adults who underwent intracameral injection of r-TPA and were receiving topical drops containing a phosphate based drug. ${ }^{1321}$ The opacification is thought to occur as a result of a temporary disturbance in endothelial function following surgery allowing calcium (from the aqueous humour) and phosphate to distribute and precipitate within the corneal stroma. ${ }^{22}$ The authors recommend cessation of such drops in patients who have received intracameral r-TPA. ${ }^{23}$ Klais et al observed mild band keratopathy 6-8 weeks postinjection but we did not document these complications in our paediatric series.

The optimal dose for intracameral administration of r-TPA remains undetermined. Using 10-12 $\mu \mathrm{g}$ of $\mathrm{r}$-TPA complete fibrinolysis has been achieved in $70 \%$ of 20 eyes in patients with fibrinous pupillary membranes secondary to a variety of causes. ${ }^{17}$ Intraocular fibrinolysis has been achieved with doses as low as $3 \mu \mathrm{g}$. ${ }^{24}$ Little difference in fibrin resolution occurs after using $50 \mu \mathrm{g}$ compared with $175 \mu \mathrm{g}$ of r-TPA. Klais et al used a dose of $10 \mu \mathrm{g}$ r-TPA in their series of children. ${ }^{2}$ We used a dose of 25 $\mu \mathrm{g}$ since it was considered a safe dose in equivalent adult studies (one patient received $10 \mu \mathrm{g}$ since there was evidence of clot dissolution during the intracameral injection). Also the option of multiple injections is not as easily available in children who require general anaesthesia as it is in adults who receive treatment under local anaesthesia. We felt the fibrinous membranes were severe and were concerned that a lower dose may not have had the desired therapeutic effect. r-TPA administration is effective for less than 3 weeks after the onset of fibrinous membrane formation following cataract surgery ${ }^{6}$ or after posterior segment surgery. ${ }^{2526}$

The disadvantage of r-TPA in children is the necessity for administration under a second general anaesthetic. Topical r-TPA has been 
used in rabbits achieving therapeutic anterior chamber concentrations and an acceleration in fibrinolysis ${ }^{27}$ using a multiple drop regimen. However, these results were not repeated in dog models $^{13}$ and are yet to be validated in humans.

In conclusion, $25 \mu \mathrm{g}$ r-TPA may be safely used following the formation of severe fibrinous membranes after paediatric cataract extraction and aids in the postoperative visual recovery. However, care must be taken to minimise all possible complications during administration, and we would therefore advise waiting at least 3 days after surgery before injecting $r$-TPA.

1 Wedrich A, Menapace R, Ries E, et al. Intracameral tissue plasminogen activator to treat severe fibrinous effusion after cataract surgery. 7 Cataract Refract Surg 1997:23:8737.

2 Klais CM, Hattenbach LO, Steinkamp GWK, et al. Intraocular recombinant tissue-plasminogen activator fibrinolysis of fibrin formation after cataract surgery in children. $\mathcal{F}$ Cataract Refract Surg 1999;25:357-61.

3 Sebestyen JG. Fibrinoid syndrome: a severe complication of vitrectomy surgery in diabetes. Ann Ophthalmol 1982;14: 8itrecto 853-6.

4 Miyake $\mathrm{K}$. The significance of inflammatory reactions following cataract extraction and intraocular lens implantation. 7 Cataract Refract Surg 1996;22:759-63.

5 Wedrich A, Menapace R, Muhlbauer-Reis E. The use of recombinant tissue plasminogen activator for intracameral fibrinolysis following cataract surgery. Int Ophthalmol 1995; 18:277-80.

6 Moon J, Chung S, Myong Y, et al. Treatment of post-cataract fibrinous membranes with tissue plasminogen activator. Ophthalmology 1992;99:1256-9.

7 Koch DD, Kohnen T. Retrospective comparison of techniques to prevent secondary cataract formation after posterior chamber intraocular lens implantation in infants and children. F Cataract Refract Surg 1997;23:657-63.

8 Simons BD, Siatkowski M, Schiffman JC, et al. Surgical technique, visual outcome, and complications of pediatric intraocular lens implantation. $\mathcal{F}$ Pediatric Ophthalmol Strabismus 1999;36:118-24.

9 Tripathi RC, Park JK, Tripathi BJ, et al. Tissue plasminogen Tripathi RC, Park JK, Tripathi BJ, et al. Tissue plasminogen activator in human aqueous and its possible ther
significance. Am $\mathcal{F}$ Ophthalmol 1988;106:719-22.

10 Yoshitomi F, Utsumi E, Hayashi M, et al. Postoperative fluctuation of tissue plasminogen activator (t-PA) in aqueous
humor of pseudophakes. $\mathcal{F}$ Cataract Refract Surg 1991;18: humor of
11 Collen D, Stassen JM, Marafino BJ Jr, et al. Biological properties of human tissue-type plasminogen activator obtained by expression of recombinant DNA in mammalian cells. $\mathcal{F}$ Pharmacol Exp Ther 1984;231:146-52.

12 Snyder RW, Lambrou FH, Williams GA. Intraocular fibrinolysis with recombinant human tissue plasminogen activator; experimental treatment in a rabbit model. Arch Ophthalmol 1987;105:1277-80.

13 Gerding PA, Hamor RE, Ramsey DT, et al. Evaluation of topically administered tissue plasminogen activator for intraocular fibrinolysis in dogs. Am 7 Vet Res 1994;55: 1368-70.

14 McDermott ML, Edelhauser HF, Hyndiuk RA, et al. Tissue plasminogen activator and the corneal endothelium. Am f Ophthalmol 1989;108:91-2.

15 Johnson MW, Olsen KR, Hernandez E, et al. Retinal toxicity of recombinant tissue plasminogen activator in the rabbit. Arch Ophthalmol 1990;108:259-63.

16 Jaffe GJ, Lewis H, Han DP, et al. Treatment of postvitrectomy fibrin pupillary block with tissue plasminopostvitrectomy fibrin pupillary block with tissue
gen activator. Am f Ophthalmol 1989;108:170-5.

17 Koerner F, Boehnke M. Clinical use of recombinant plasminogen activator for intraocular fibrinolysis. Germ $\mathcal{f}$ Ophthalmol 1992:1:354-60.

18 Laatikainen L, Mattila J. The use of tissue plasminogen activator in post-traumatic hyphema. Graefes Arch Clin Exp Ophthalmol 1996;234:67-8.

19 Lewis H, Medendorp S. Tissue plasminogen activatorassisted surgical excision of subfoveal choroidal neovascularization in age-related macular degeneration. Ophthalmology 1997;104:1847-51.

20 Johnson RN, Olsen K, Hernandez E. Tissue plasminogen activator treatment of postoperative intraocular fibrin. Ophthalmology 1988;95:592-6.

21 Wollensak G, Meyer JH, Loffler $\mathrm{KU}$, et al. Band-like keratopathy after treatment of postoperative fibrin reaction with tissue plasminogen activator. Klin Monatsbl Augenheilkd 1996;209:43-6.

22 Hesse L, Nebeling B, Kauffmann T. Etiology of corneal opacities after plasminogen activator-induced fibrinolysis of the anterior chamber. Ophthalmologe 1999;96:448-52.

23 Althaus C, Schelle C, Sundmacher R. Acute band-shaped keratopathy after intraocular fibrinolysis with recombinant tissue plasminogen activator (rt-PA). Klin Monatsbl Augenheilkd 1996;209:318-21.

24 Heiligenhaus A, Steinmetz B, Lapuente R, et al. Recombinant tissue plasminogen activator in cases with fibrin formation after cataract surgery: a prospective randomised multicentre study. Br F Ophthalmol 1988;82:810-15.

25 Abrams GW. Prepared discussion remark presented at the 3rd International Congress of Vitreo-Retinal Surgery, Rome, 12-14 September 1991.

26 Folk JC, Hershey JM, Rivers MB. Lack of effectiveness of tissue plasminogen activator 20 or more days after tissue plasminogen activator 20 or mo
vitrectomy. Arch Ophthalmol 1991;109:614.

27 Lim JI. Fiscella R, Tessler H, et al. Intraocular penetration of topical tissue plasminogen activator. Arch Ophthalmol 1991;109:714-7. 